\title{
Meandering Process and Migration Architecture: Based on the Nowitna River
}

\author{
Le Chen ${ }^{1,2}$, Zhipeng Lin ${ }^{1,2}$, Yin Taiju ${ }^{1,2}$, Jingfu Shan ${ }^{1,2}$, Qianjun $\operatorname{Sun}^{3} \&$ Fei Wang ${ }^{4}$ \\ ${ }^{1}$ Key Laboratory of Exploration Technologies for Oil and Gas Resources, Ministry of Education, Yangtze \\ University, Wuhan, China \\ ${ }^{2}$ School of Geosciences, Yangtze University, Wuhan, China \\ ${ }^{3}$ School of Energy Resources, China University of Geosciences, Beijing, China \\ ${ }^{4}$ Gas Production Company of Daqing Oilfield Limited Company, Daqing, China \\ First author: Le Chen, School of Geosciences, Yangtze University, Caidian, Wuhan, China. Tel: 86-131-0066-3328. \\ E-mail: chenle92@yangtzeu.edu.cn \\ Corresponding author: Zhipeng Lin, School of Geosciences, Yangtze University, Caidian, Wuhan, China. Tel: \\ 86-136-9734-7719. E-mail: linzp93@yangtzeu.edu.cn
}

Received: March 28, 2017

Accepted: March 17, 2017 Online Published: June 17, 2017

doi:10.5539/esr.v6n2p76

URL: https://doi.org/10.5539/esr.v6n2p76

\begin{abstract}
The meandering process has always been the topic through years and still remains a lot of unsolved mysteries. One of the most important focus is the migration architectures and models that the meandering channels follow. This article chooses the Nowitna River as the study object of the typical meandering river with high migratory processes. Though the high-resolution historical satellite images by the techniques of Google Earth and ACME Mapper, 50 meanders in the river is studied and 6 of which are chosen for meticulous characterization. During the process, the planform structure of meandering channel is re-examined and 29 kinds of architecture elements are systematically established. More importantly, in order to make a fine quantitative characterization of the channel structure of meandering river, 5 kinds of characterization parameters are proposed, extraordinarily, the parameters of the difference of along-current deflection angle, a difference of counter-current deflection angle, and expansion coefficient, these three are firstly brought forward and applied introduction. In addition, the conception of sinuosity index and curvature are also different from the original definition. Though these architectures elements the meandering process and migration structure of the Nowitna River is demonstrated. 6 kinds of planform migration structures is revealed with the quantitative characterization of characterization parameters and 9 species of meandering channel migration patterns are concluded and discussed.
\end{abstract}

Keywords: meandering process, migration architecture, migration patterns, Nowitna River, characterization parameters, satellite images

\section{Introduction}

Many classical articles at home and abroad try to analyze the three-dimensional dynamic structure of the river from the aspects of scale estimation, numerical simulation, and hydrodynamics, such as Leopold and Maddock(1953), had made some achievements on river hydrodynamic characteristics, meandering structure, pattern(1957) and geomorphological features(1960) and so on. Wolman and Miller(1960) thought that the periodicity of flow change is an important factor in controlling the geomorphology through the analysis of the geomorphic process, and followed the examples of tracking the evolution of the meandering process. Williams(1978) proposed the definition and calculation of bank-full discharge by analyzing the river bank flow and speculated its influence on the channel morphology. Brice(1974) put forward four main categories of meander loops, including simple symmetrical, simple asymmetrical, compound symmetrical, and compound asymmetrical. Miall(1985, 2013, 2014, 2016) indicated that the best clues were always determined on the visible field outcrops, which could be understood from the configuration elements to the evolution of deposition. Through the three-dimensional model of simulating the migration process of meandering, Willis and Tang(2010) further demonstrated the translation, rotation, expansion and complex patterns of the meandering loops. Ielpi(2014), Ghinassi(2014) and $\mathrm{Wu}(2016)$ and others recently have begun to try to reconstruct the 
characteristics of the ancient channel and analyze the morphodynamic process. In the whole view, though there are large numbers of works on the meandering structure, studies on migration architecture of channel planform have not yet effectively combined with the geomorphological theory. Therefore, The migration structure of meandering rivers needs to be further strengthened.

The planform migration architecture and process of a meandering river could undoubtedly promote awareness of the reestablishment course of paleochannel of meandering rivers, show the tendency of combination with modern and ancient sedimentary systems (Leeder, 1973; Blum, Martin, Milliken, \& Garvin, 2013; Schuurman, Kleinhans, \& Middelkoop, 2016; Kasvi, Laamanen, Lotsari, \& Alho, 2017; Lin, Shan, \& Chen, 2017b). However, the migration rule of the channel is complex, and the traditional method is difficult to accurately characterize the internal architecture of the reservoir unit and predict the hydrocarbon-derived model of oil and gas production process(Xue, 1991; Wu \& Wang, 1999; Mu, 2000; Yin, Zhang, Zhao, Fan, \& Li, 2001; Hu, 2016; Hu, Chen, Fan, $\& \mathrm{Hu}, 2017)$. By characterizing and analyzing the rules of migration architecture of meandering rivers, it will be easier to guide and understand the distribution characteristics of underground sand bodies (Sui, 2006; Willis \& Tang, 2010; Mithun, Dabojani, \& Misbah, 2012; Hu, Fan, et al., 2017; Lin, 2017). Although an increasing amount of literature focus on the ancient and modern fluvial system, the evolutional process analysis of geomorphology of meanders remains an issue (Willis \& Tang, 2010; Ielpi \& Ghinassi, 2014; Debnath, Pan, Ahmed, \& Bhowmik, 2017; Lin, Shan, \& Chen, 2017a).

This paper crucially aims to focus on four targets, (1) A comprehensive scheme for characterizes the morphological elements of planform architecture of meandering rivers; (2) New method of characterization factors, including descriptive elements and dynamic parameters; (3) Geomorphology process and migration characteristics of different meandering channels; (4) a comprehensive set of model for channel migration structure of meandering rivers. By means of high-resolution historical satellite images from Google Earth and ACME Mapper (A kind of software based on Google Earth), the research characterizes on Nowitna River, which is relatively in the considerable preservation condition of the natural architecture and free from the impact of human beings.

\section{Geology Setting}

The paper has a focus on the Nowitna River, whose population distribution is relatively sparse and the ecosystem and structure are in good condition, and the channel is easier to observe. Within this river, 50 meanders are selected for investigation and 6 of them are utilized for comprehensive characterizing.

The Nowitna River is located in the Alaska National Wildlife Refuge, a tributary of the Yukon River, which is a typical meandering river flowing from the north of Kuskokwim Mountains, through National Wildlife Refuge and flows to the southwest of Tanana to import Yukon River. The total length is about $455.45 \mathrm{~km}$ and basin area is about $576.27 \mathrm{~km}^{2}$, with a large number of lakes and swamps, surrounded by terrain flat, or rolling hills and lush riverside vegetation; Length of $362 \mathrm{~km}$ of the river was designated as "wild" rivers, and therefore very little at this stage is affected by human factors, the structure is very well preserved. The study reach lies from the estuary of Nowitna River and Yukon River, with coordinates of $64^{\circ} 53{ }^{\prime} \mathrm{N}$ and $154^{\circ} 15^{\prime} \mathrm{W}$, southward to the coordinates of $64^{\circ} 36^{\prime} \mathrm{N}$ and $154^{\circ} 27^{\prime} \mathrm{W}$, as is shown in Fig. 1 NR: I-II, with a length of $97.89 \mathrm{~km}$ and a straight line distance of $35.53 \mathrm{~km}$. The migration phenomenon is obvious and the characteristics are easy to see.

\section{Methods and Techniques}

Nowadays the description and characterization of the meandering process and structure are still principally focusing on the interpretation of microfacies(He \& Wang, 2008; Zhu, 2008; Feng, 2013; Xu et al., 2016; Kasvi et al., 2017). Nevertheless, The planform architecture of a meandering channel is the basis of depicting the channel migration process(Leopold \& Wolman, 1957; Schumm \& Lichty, 1963; Hooke, 1984; Kondolf, 2006; Shan et al., 2015). This paper systematically establishes 29 architecture elements, more importantly, 5 kinds of characterization parameters are proposed in order to make a fine quantitative characterization of the channel structure of meandering river. Overall, the elements can be divided into 3 parts: static elements, dynamic elements, and characterization parameters. 


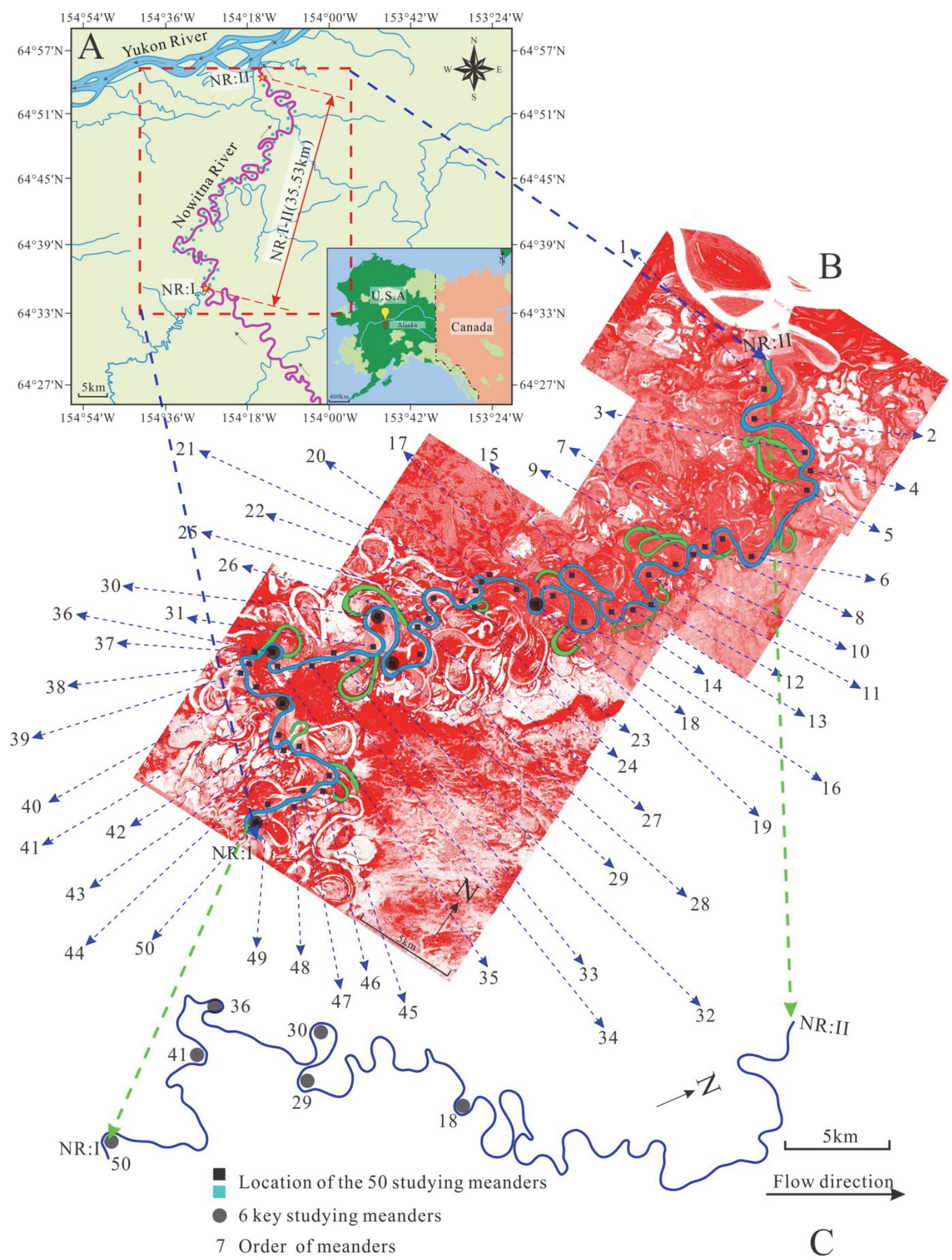

Figure 1. Location map of the Nowitna River: A 50 meanders are investigated in reach NR: I-II, coordinate information comes from Google Earth and ACME Mapper. B the details of the 50 studying meanders in the composite satellite images of Google Earth, showing the orders of the meanders. C extracted centerline(see

Figure 2) from the research drainage area of the Nowitna River, marked the 6 main studying meanders 


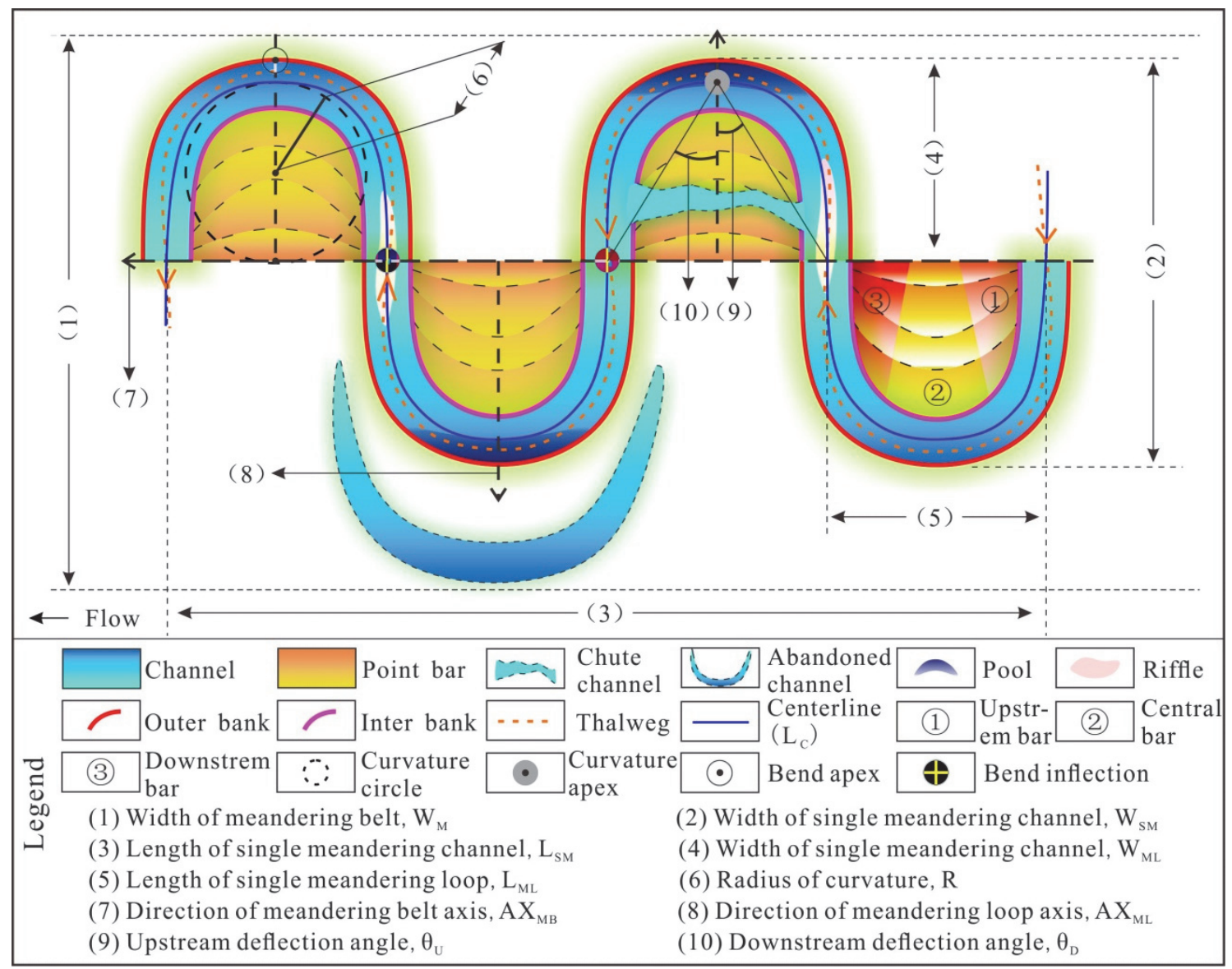

Figure 2. Planform architecture elements model of migration architecture of the meandering river within the ideal situation, which includes 17 static elements and 12 dynamic elements

\subsection{Static Elements}

Elements that characterize the channel units and the abstract concept of streamline are defined as the static elements. It principally includes the in-channel elements: main channel, pool, riffle, thalweg, centerline, bend inflection, and curvature apex. And the outbank elements are: meandering belt, point bar (upstream bar, central bar, downstream bar), chute channel, outer bank (concave bank), the inner bank (convex bank), meandering loop (meander or bend), abandoned channel, floodplain(overbank), curvature circle, and bend apex. Among them, the most important elements for migration structure are the meandering loop, centerline, bend inflection, curvature apex, curvature circle, point bar, and thalweg.

Meandering loop, also known as the river bend, is a certain ring bending of the river meandering process, as is shown in Figure 2, a range of a single meandering loop is confined by the elements of (4) and (5). The centerline is the connection of the multi-midpoint between the outer and inner edge of the river bank, as is shown in Figure 2 of the blue solid line. Bend inflection is the transitional position of two adjacent meandering loops, which is also the intersection of the meandering axis line $\left(\mathrm{AX}_{\mathrm{M}}\right)$ and centerline morphologically, as shown in Figure 2, (7). Curvature apex is the midpoint of the bend apex and interbank apex and is also the intersection of the meandering loop axis line $\left(\mathrm{AX}_{\mathrm{ML}}\right)$ and the centerline. It can be seen in Figure 2. The curvature circle is a geometric circle representing the degree of curvature of a single meandering loop, as is shown in Figure 2. The center of the circle generally falls near the central bar. The greater the perimeter is, the bigger the curvature is. Point bar is a sophisticated sedimentary unit for channel migration and sediment accumulation. See Figure 2, it can be qualitatively subdivided into an upstream bar, central bar and downstream bar. The thalweg, also known as the deepest valley bottom line, is the line connecting the lowest altitude point of the channel, as is shown in Figure 2 with the orange dotted line.

\subsection{Dynamic Elements}

Elements that extracted from the static elements, which is the quantitative reflection and presentation of the 
channel structure, are defined as the dynamic elements. Those only consider the value of magnitude are called scalar elements while those have direction attribute are vector elements. The former includes: width of meandering belt $\left(\mathrm{W}_{\mathrm{M}}\right)$, length of meandering belt $\left(\mathrm{L}_{\mathrm{M}}\right)$, width of single meandering channel $\left(\mathrm{W}_{\mathrm{SM}}\right)$, length of single meandering channel $\left(\mathrm{L}_{\mathrm{SM}}\right)$, width of single meandering loop $\left(\mathrm{W}_{\mathrm{ML}}\right)$, length of single meandering $\operatorname{loop}\left(\mathrm{L}_{\mathrm{ML}}\right)$, length of channel centerline $\left(\mathrm{L}_{\mathrm{C}}\right)$, and radius of curvature $(\mathrm{R})$. While the latter includes: meandering belt axis $\left(\mathrm{AX} \mathrm{X}_{\mathrm{MB}}\right)$, meandering loop axis $\left(\mathrm{AX} \mathrm{XL}_{\mathrm{ML}}\right)$, upstream deflection angle $\left(\theta_{\mathrm{U}}\right)$, and downstream deflection angle $\left(\theta_{\mathrm{D}}\right)$, (Table 1, Figure 2).

The width of the meandering belt $\left(\mathrm{W}_{\mathrm{M}}\right)$ refers to the width of the multi-stage compound channel, as shown in Figure 2 (1), including the widest distance of the whole compound river; the range in the study area is $8700 \mathrm{~m} \sim$ $12000 \mathrm{~m}$. The length of the meandering belt $\left(\mathrm{L}_{\mathrm{M}}\right)$ refers to the length of the full multi-stage compound channel with cross-domain scope, that is, the length of meandering belt axis from the very beginning to the end of a complete stream. Figure 2 can not express the whole river, so there is no marked with the length of the meandering belt. Here the length of Nowitna River is $55457.96 \mathrm{~m}$. The width of the single meandering channel ( $\mathrm{W}_{\mathrm{SM}}$ ) refers to the migration width of a single channel, as is shown in Figure 2 (2), the width of this area varies in $1700 \mathrm{~m} \sim 4100 \mathrm{~m}$. The length of the single meandering channel $\left(\mathrm{L}_{\mathrm{SM}}\right)$ refers to the length of a single channel with cross-domain scope, as is shown in Figure 2 (3) length. The value in this area is $3600 \mathrm{~m} \sim 7900 \mathrm{~m}$. The width of the single meandering loop $\left(\mathrm{W}_{\mathrm{ML}}\right)$ refers to the vertical distance of the bend apex to the meandering belt axis, as is shown in Figure $2(4)$, the value in this area is $650 \mathrm{~m} \sim 2200 \mathrm{~m}$. The length of single meandering loop ( $\mathrm{L}_{\mathrm{ML}}$ ) refers to the straight line distance between the adjacent two bend inflections, as is shown in Figure 2 (5). The value here is $420 \mathrm{~m} \sim 1200 \mathrm{~m}$. The length of channel centerline $\left(L_{C}\right)$ is shown in Figure 2 as the length of the blue solid line. The range here is $1500 \mathrm{~m} \sim 4500 \mathrm{~m}$ according to research needs. The radius of curvature $(\mathrm{R})$ is the radius of the curvature circle, as is shown in Figure 2 (6). Radius here changes between $300 \mathrm{~m} \sim 800 \mathrm{~m}$. The meandering belt axis $\left(\mathrm{AX} \mathrm{MB}_{\mathrm{MB}}\right)$ refers to the central axis of the swing of a meandering channel, it is the connection of each bend inflection with the direction following with water flow, as is shown in Figure 2 (7). When focusing on a single meander, the length is approximately equal to the length of the single meandering loop. In this study the length of $\mathrm{AX}_{\mathrm{MB}}$ is $420 \mathrm{~m} \sim 1200 \mathrm{~m}$, the direction is $109^{\circ} \sim 280^{\circ}$. The meandering loop axis $(\mathrm{AX} \mathrm{ML})$ refers to the central axis of the meandering loops, which is the connection between the bend apex and the midpoint of the corresponding two bend inflection, as is shown in Figure $2(8)$. The direction in this paper is $16^{\circ} \sim 170^{\circ}$. The upstream deflection angle $\left(\theta_{\mathrm{U}}\right)$ and downstream deflection angle $\left(\theta_{\mathrm{D}}\right)$ are firstly proposed in this paper. While the former is the angle between connecting-line of curvature apex with corresponding upstream bend inflection and the meandering loop axis, as is shown in Figure 2 (9); the latter refers to the angle between connecting-line of curvature apex with corresponding downstream bend inflection and the meandering loop axis, as is shown in Figure $2(10)$. In this study $\theta_{\mathrm{U}}$ is $18^{\circ} \sim 43^{\circ}$ and $\theta_{\mathrm{D}}$ is $11^{\circ} \sim 46^{\circ}$.

\subsection{Characterization Parameters}

The static and dynamic elements are representative of the characteristics of the channel structure, however, in order to quantify the factors of the migration architecture, structural elements need to be quantitatively represented, that is, characterization parameters. According to the structural elements above, five characterization parameters are extracted: sinuosity index (S), curvature $(\mathrm{C})$, difference of along-current deflection angle $(\Delta \theta)$, difference of counter-current deflection angle $\left(\Delta \theta^{\prime}\right)$, and expansion coefficient $\left(\mathrm{K}_{\mathrm{M}}\right)$, in which the parameters of $\Delta \theta, \Delta \theta^{\prime}$ and $\mathrm{K}_{\mathrm{M}}$ are presented for the first time in this paper while the parameters of $\mathrm{S}$ and $\mathrm{C}$ is also demonstrated with a new definition. The basic elements and characterization parameters of the reach segment in Nowitna River are shown in Table 1.

Sinuosity index (S) refers to the ratio of the length of centerline to the corresponding meandering belt axis, which is adoped to indicate the bending degree. The definition of the sinuosity previously is the ratio of the length of the channel to the valley. However, evidently, the problem is that how to understand the definition of the length of a channel, valley, outer bank line, interbank line, thalweg, and centerline, or the length of the straight line of the starting and ending points of the river. The distinction is not so clear enough that the concept of sinuosity is easily confused. However, in our new definition, using the length of the centerline to represent the length of a river, the confusion of channel length can get unified. Simultaneously, the utilization of the length of meandering belt axis instead of length of valley, on the one hand, will not cause the fuzzy of concept; As mentioned earlier, the length of meandering belt axis, rather than the straight distance from the beginning to the end point, could accurately reflect the actual sinuosity situation, since it has taken into account the migration of channel morphology with the terrain meandering factors, rather than simplifying the distance as a straight line. Expressed as a formula can be written: 


$$
S=L_{C} /\left|A X_{M B}\right|
$$

Curvature $(\mathrm{C})$ refers to the reciprocal of curvature radius $(\mathrm{R})$ of the corresponding meander, which is taken to indicate the degree and scale of a meander. The greater the curvature is, the greater the degree of bending is. The method of calculating curvature according to the ratio between the arc length and the diameter of a point bar(Shi, Hu, Fen, \& Liu, 2012) has a certain degree of ambiguity, because the extracted diameter and the arc length from the irregularity of the point bar are not clear for lack of accurate definition. Here the choice of $\mathrm{R}$ is of great concern, which is never a simple half length of the so-called diameter of a point bar. Firstly, through the two bend inflections, one can determine the starting and end point of the meander. Secondly, define the curvature apex and control the shape of the entire meandering loop. Ultimately, through these three points: two bend inflections and one curvature apex, thus the obtained curvature circle and $\mathrm{R}$ could be an effectively better representative of curvature. Expressed as the formula below:

$$
C=1 / R
$$

The difference of along-current deflection angle $(\Delta \theta)$ refers to the difference between the upstream deflection angle $\left(\theta_{\mathrm{U}}\right)$ and downstream deflection angle $\left(\theta_{\mathrm{D}}\right)$, reflecting the symmetry of a bend. The closer the value is to 0 , the higher the symmetry is. Moreover, while the value is positive and greater, the curvature apex is indicated closer to the upstream bend inflection, showing a tendency of counter-current rotation. On the contrary, the difference is negative and smaller, the curvature apex is indicated closer the downstream bend inflection, showing a tendency of along-current rotation. Formula is:

$$
\Delta \theta=\theta_{U}-\theta_{D}
$$

Meanwhile, contrary to $\Delta \theta$, the $\Delta \theta^{\prime}$, difference of counter-current deflection angle, refers to the difference between the downstream deflection angle $\left(\theta_{\mathrm{D}}\right)$ and upstream deflection angle $\left(\theta_{\mathrm{U}}\right)$, with objective similarity and perspective diversity. The closer the value is to 0 , the higher the symmetry is. While the value is positive and greater, the curvature apex is indicated closer to the downstream bend inflection, showing a tendency of along-current rotation. On the contrary, the difference is negative and smaller, the curvature apex is indicated closer the upstream bend inflection, showing a tendency of counter-current rotation. Write as:

$$
\Delta \theta^{\prime}=\theta_{D}-\theta_{C}
$$

Expansion coefficient $\left(\mathrm{K}_{\mathrm{M}}\right)$ refers to the ratio of the length of single meandering loop $\left(\mathrm{L}_{\mathrm{ML}}\right)$ to the diameter of curvature circle (2R). Basically, this coefficient could represent the changes of meandering shape because it is dominated by the elements of both bend reflection and curvature apex. When the meandering loop migrates outward with expansion, the curvature diameter (2R) tends to be generally larger with the control of bend reflection, while the length of single meandering loop relatively changes less. Thus the value of $\mathrm{K}_{\mathrm{M}}$ decreases gradually to 1 . When the meander expands to a certain extent, constriction process begins. Within the course, the curvature diameter is generally going to be larger than the length of the single meandering loop, leading to the value of $K_{M}$ decreases to less than 1 . This is the course of how the $K_{M}$ could quantitatively reflect the situation of expansion and constriction process of a channel. See as a formula:

$$
K_{M}=L_{M L} / 2 R
$$

\begin{tabular}{|c|c|c|c|c|c|c|}
\hline Elements & Nowitna $R$ & iver & & & & \\
\hline Meander & 18 & 29 & 30 & 36 & 41 & 50 \\
\hline Latitude & $64^{\circ} 45^{\prime} \mathrm{N}$ & $64^{\circ} 41^{\prime} \mathrm{N}$ & $64^{\circ} 42^{\prime} \mathrm{N}$ & $64^{\circ} 40^{\prime} \mathrm{N}$ & $64^{\circ} 39^{\prime} \mathrm{N}$ & $64^{\circ} 35^{\prime} \mathrm{N}$ \\
\hline Longitude & $154^{\circ} 20^{\prime} \mathrm{W}$ & $154^{\circ} 26^{\prime} \mathrm{W}$ & $154^{\circ} 28^{\prime} \mathrm{W}$ & $154^{\circ} 33^{\prime} \mathrm{W}$ & $154^{\circ} 30^{\prime} \mathrm{W}$ & $154^{\circ} 21^{\prime} \mathrm{W}$ \\
\hline $\mathrm{W}_{\mathrm{M}} / \mathrm{m}$ & 9299.9 & 10283.3 & 10327.0 & 12014.7 & 10044.3 & 8770.7 \\
\hline $\mathrm{L}_{\mathrm{M}} / \mathrm{m}$ & 55458.0 & 55458.0 & 55458.0 & 55458.0 & 55458.0 & 55458.0 \\
\hline $\mathrm{W}_{\mathrm{SM}} / \mathrm{m}$ & 1774.7 & 4111.8 & 3941.5 & 1873.8 & 3201.4 & 2217.4 \\
\hline $\mathrm{L}_{\mathrm{SM}} / \mathrm{m}$ & 3660.9 & 6970.9 & 7339.3 & 6217.5 & 7918.2 & 3336.5 \\
\hline $\mathrm{W}_{\mathrm{ML}} / \mathrm{m}$ & 654.8 & 1022.0 & 2269.6 & 700.2 & 715.9 & 592.0 \\
\hline $\mathrm{L}_{\mathrm{ML}} / \mathrm{m}$ & 727.9 & 1078.1 & 1186.1 & 684.8 & 1221.3 & 425.6 \\
\hline $\mathrm{L}_{\mathrm{C}} / \mathrm{m}$ & 1608.9 & 2487.3 & 4578.9 & 1884.5 & 2300.0 & 1547.8 \\
\hline $\mathrm{R} / \mathrm{m}$ & 300.1 & 465.8 & 866.5 & 355.3 & 456.6 & 296.9 \\
\hline$\left|\mathrm{AX}_{\mathrm{MB}}\right| / \mathrm{m}$ & 727.9 & 1078.1 & 1186.1 & 684.8 & 12213 & 425.6 \\
\hline
\end{tabular}

Table 1. The Architecture Elements and Parameters of the 6 Key Studying Meanders in the reach NR: I-II of Nowitna River 


\begin{tabular}{lllllll}
$\mathrm{AX}_{\mathrm{MB}} /{ }^{\circ}$ & 237.2 & 292.3 & 278.6 & 279.8 & 109.8 & 130.9 \\
$\mathrm{AX}_{\mathrm{ML}} /{ }^{\circ}$ & 143.7 & 174.2 & 311.2 & 16.8 & 58.5 & 29.3 \\
$\theta_{\mathrm{U}} /{ }^{\circ}$ & 32 & 21 & 23 & 26 & 43 & 18 \\
$\theta_{\mathrm{D}} /{ }^{\circ}$ & 34 & 46 & 11 & 30 & 22 & 22 \\
$\mathrm{~S}$ & 2.21 & 2.31 & 3.86 & 2.75 & 1.88 & 3.64 \\
$\mathrm{C}$ & 0.0033 & 0.0021 & 0.0012 & 0.0028 & 0.0022 & 0.0034 \\
$\Delta \theta / \circ$ & -2 & -25 & 12 & -4 & 21 & -4 \\
$\Delta \theta^{\prime} /{ }^{\circ}$ & 2 & 25 & -12 & 4 & -21 & 4 \\
$\mathrm{~K}_{\mathrm{M}}$ & 1.21 & 1.16 & 0.68 & 0.96 & 1.34 & 0.72 \\
\hline
\end{tabular}

Note: $\mathrm{W}_{\mathrm{M}}$ : width of meandering belt, $\mathrm{L}_{\mathrm{M}}$ : length of meandering belt, $\mathrm{W}_{\mathrm{SM}}$ : width of single meandering channel, $\mathrm{L}_{\mathrm{SM}}$ : length of single meandering channel, $\mathrm{W}_{\mathrm{ML}}$ : width of single meandering loop, $\mathrm{L}_{\mathrm{ML}}$ : length of single meandering loop, $\mathrm{L}_{\mathrm{C}}$ : length of channel centerline, $\mathrm{R}$ : radius of curvature, $\left|\mathrm{AX}_{\mathrm{MB}}\right|$ : length of meandering belt axis, $\mathrm{AX}_{\mathrm{MB}}$ : direction of meandering belt axis, $\mathrm{AX}_{\mathrm{ML}}$ : direction of meandering loop axis, $\theta_{\mathrm{U}}$ : upstream deflection angle, $\theta_{\mathrm{D}}$ : downstream deflection angle, $\mathrm{S}$ : sinuosity index, $\mathrm{C}$ : curvature, $\Delta \theta$ : difference of along-current deflection angle, $\Delta \theta^{\prime}$ : difference of counter-current deflection angle, $\mathrm{K}_{\mathrm{M}}$ : expansion coefficient.

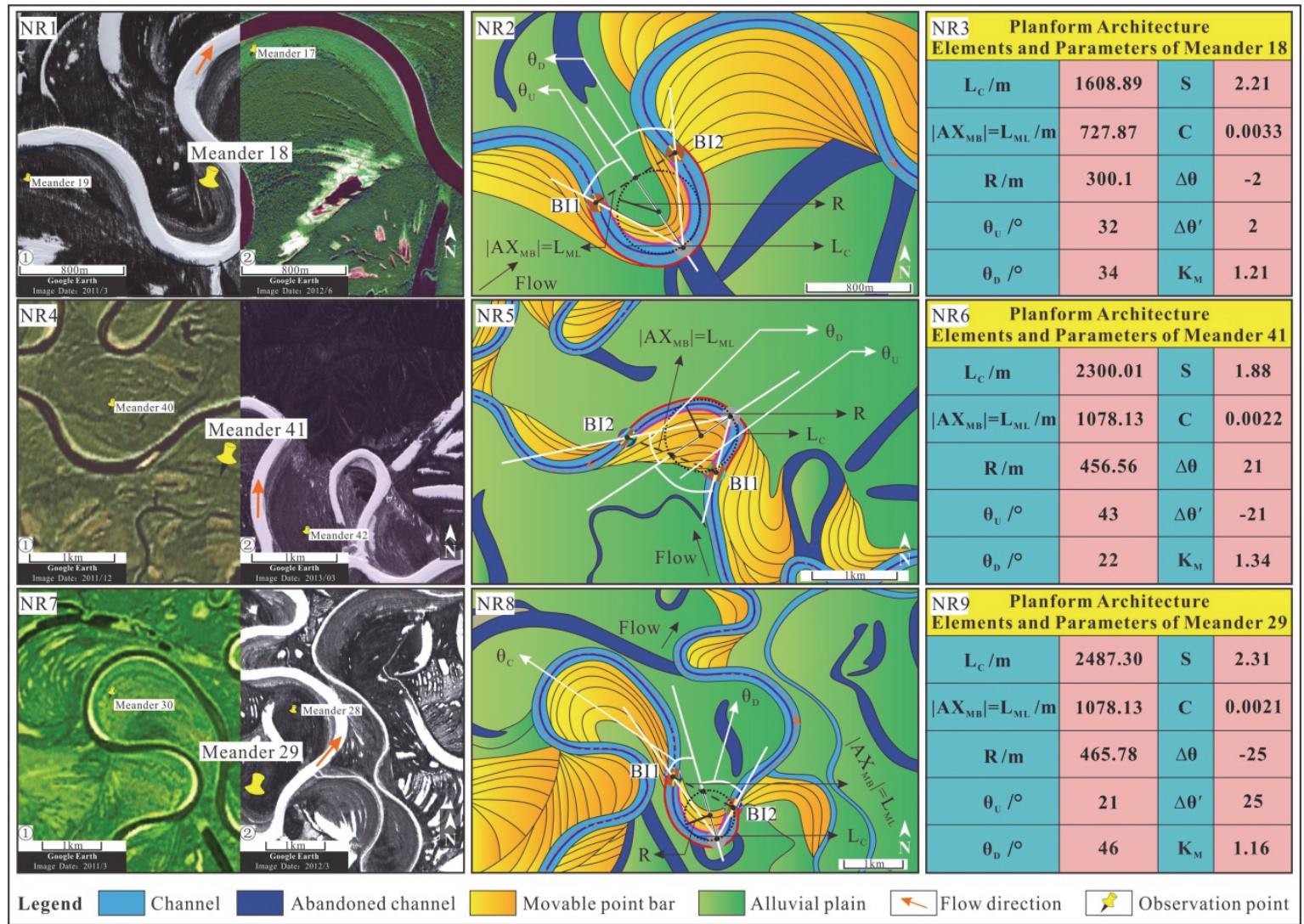

Figure 3. Planform migration structures of the Expansion Structure of the Nowitna River

NR1-NR3 is the performance of Symmetrical Expansion Structure in meander 18, while NR1 shows the satellite images taken in the last 2 years and coordinates are $64^{\circ} 45^{\prime} \mathrm{N}$ and $154^{\circ} 20^{\prime} \mathrm{W}$; NR2 shows the planform migration structures in details, and NR3 shows the statistical data of planform migration architecture elements and parameters of meander 18. NR4-NR6 is the performance of Upstream Rotation Expansion Structure in meander 41 , while NR4 shows the satellite images taken in the last 2 years and coordinates are $64^{\circ} 39^{\prime} \mathrm{N}, 154^{\circ} 30^{\prime} \mathrm{W}$; NR5 shows the planform migration structures in details, and NR7 shows the statistical data of planform migration architecture elements and parameters of meander 41. NR7-NR9 is the performance of Downstream Rotation Expansion Structure in meander 29, while NR7 shows the satellite images taken in the last 2 years and coordinates are $64^{\circ} 41^{\prime} \mathrm{N}, 154^{\circ} 26^{\prime} \mathrm{W}$; NR8 shows the planform migration structures in details, and NR9 shows the statistical data of planform migration architecture elements and parameters of meander 29. Images and coordinates information come from Google Earth and ACME Mapper 


\section{Results}

In the research area of Nowitna River, 50 subjects are examined and 6 cases are conducted with quantitative study of the meandering channel with the characterization parameters. Meanwhile, the migration structures of the channel in the Nowitna River are followed by the expansion and constriction structures, which are demonstrated as below (Figure 3 and 4):

\subsection{Expansion Structure}

The Expansion Structure can be specifically subdivided into 3 parts (Figure 3): Symmetrical Expansion Structure, Upstream Rotation Expansion Structure, and Downstream Rotation Expansion Structure. The concrete study is conducted with the meander 18, 29, and 41.

\subsubsection{Symmetrical Expansion Structure}

The meandering loop continuously erodes the outer banks and the symmetry is good, $\mathrm{K}_{\mathrm{M}}$ is greater than 1 and $\Delta \theta$ is close to $0^{\circ}$, this is the Symmetrical Expansion Structure. As is shown in Figure 3 NR1-NR3, NR1 shows the satellite images of meander 18 from years 2011 to 2012, the migration process is not obvious. According to the planform migration architecture of NR2 and characterization parameters of NR3, we can see that the value of S is $2.21, \mathrm{C}$ is 0.0033 , reflecting that the bending degree is in general; $\Delta \theta$ is $-2^{\circ}$ and $\Delta \theta^{\prime}$ is $2^{\circ}$, indicating that the symmetry of the meander is relatively great, with a slight trend of along-current rotation. $\mathrm{K}_{\mathrm{M}}$ is 1.21 , indicating that the meander is in the expansion period, and the expanding degree is increasing.

\subsubsection{Upstream Rotation Expansion Structure}

The meandering loop continuously erodes the outer banks with curvature apex being closer to the upstream bend inflection, showing a tendency of counter-current rotation, $K_{M}$ is greater than 1 and $\Delta \theta$ is positive, this is the Upstream Rotation Expansion Structure. As is shown in Figure 3 NR4-NR6, NR4 shows that from years 2011 to 2013, the migration of the meander 41 in the Nowitna River is not clear. According to the planform migration architecture of NR5 and characterization parameters of NR6, it can be seen that the value of S is $1.88, \mathrm{C}$ is 0.0028 , reflecting a greater degree of bending; $\Delta \theta$ is $21^{\circ}$ and $\Delta \theta^{\prime}$ is $-21^{\circ}$, indicating that the curvature apex is closer to the upstream bend inflection with the tendency of counter-current rotation. $\mathrm{K}_{\mathrm{M}}$ is 1.34 , indicating that the river bend is in the expansion period with an c degree.

\subsubsection{Downstream Rotation Expansion Structure}

The meandering loop continuously erodes the outer banks with curvature apex being closer to the downstream bend inflection, showing a tendency of along-current rotation, $K_{M}$ is greater than 1 and $\Delta \theta$ is negative, this is the Downstream Rotation Expansion Structure. As is shown in Figure 3 NR7-NR9, NR7 shows that from years 2011 to 2012, the migration process of meander 29 is slow, and it is shown that the value of $\mathrm{S}$ is 2.31 and $\mathrm{C}$ is 0.0021 . According to the planform migration architecture of NR8 and characterization parameters of NR9, reflecting a greater degree of bending; $\Delta \theta$ is $-25^{\circ}$ and $\Delta \theta^{\prime}$ is $25^{\circ}$, indicating that the curvature apex is closer to the downstream bend inflection with the tendency of along-current rotation. $\mathrm{K}_{\mathrm{M}} 1.16$, indicating that the river is in the expansion period with an increasing degree.

\subsection{Constriction Structure}

The Constriction Structure can also be specifically subdivided into 3 parts (Figure 4): Symmetrical Constriction Structure, Upstream Rotation Constriction Structure, and Downstream Rotation Constriction Structure. The concrete study is conducted with the meander 36,30 , and 50.

\subsubsection{Symmetrical Constriction Structure}

The process of outward expansion of the meandering loop slows down and the symmetry is maintained, and the trend of cut-off is starting gradually near the bend inflections. $K_{M}$ is less than 1 and $\Delta \theta$ is close to $0^{\circ}$, this is the Symmetrical Constriction Structure. As is shown in Figure 4 NR10-NR12, NR10 shows the satellite images of meander 36 from years 2011 to 2013, the migration process is relatively slow. According to the planform migration architecture of NR11 and characterization parameters of NR12, it can be seen that the value of $\mathrm{S}$ is $2.75, \mathrm{C}$ is 0.0028 , reflecting the higher bending degree; $\Delta \theta$ is $-4^{\circ}$ and $\Delta \theta^{\prime}$ is $4^{\circ}$, indicating that the symmetry of the bend is relatively better with a slight trend of along-current rotation. $\mathrm{K}_{\mathrm{M}}$ is 0.96 , revealing that the river is in the constriction period, and the degree of constriction is small. 


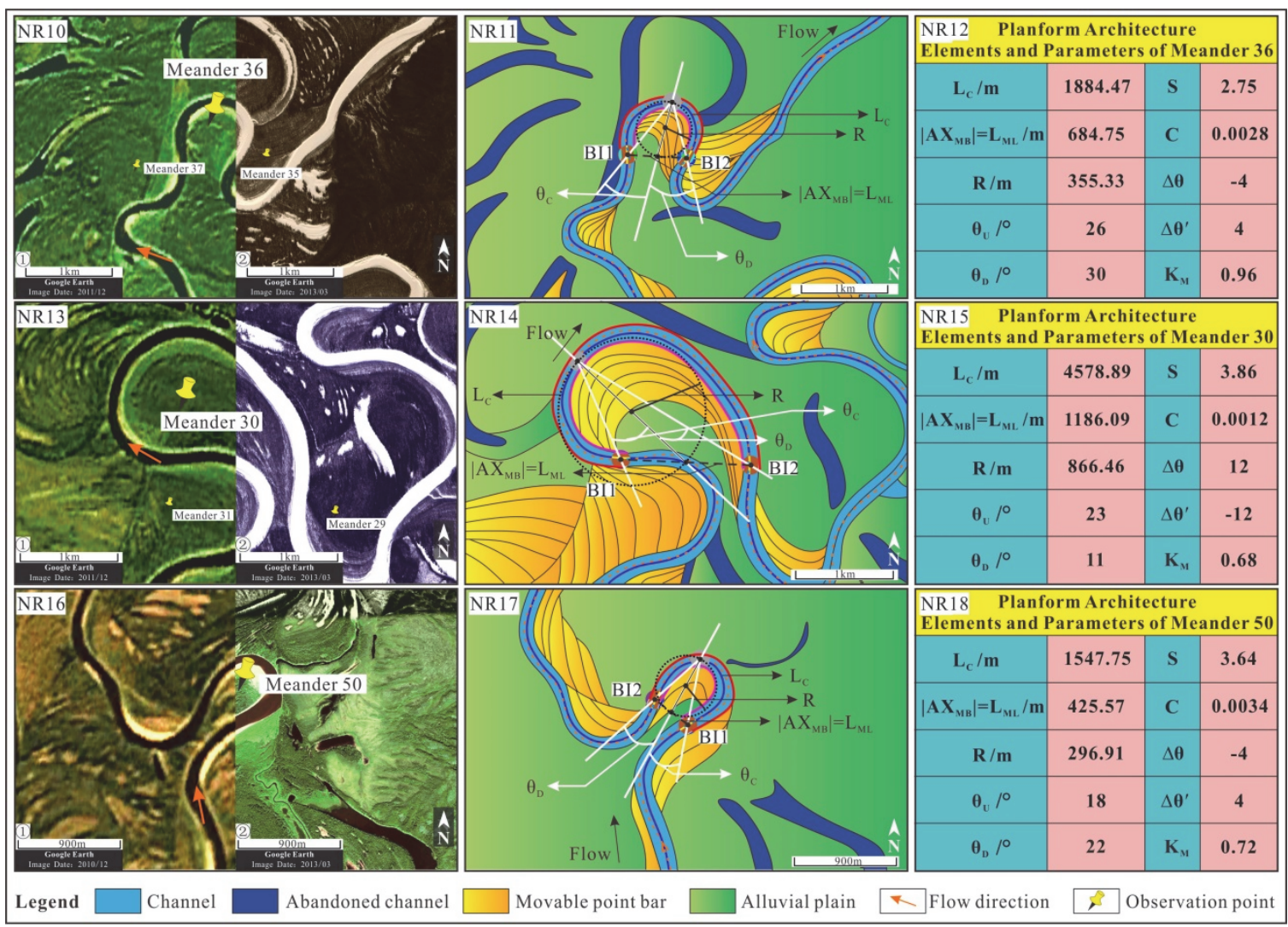

Figure 4. Planform migration structures of the Constriction Structure of the Nowitna River

NR10-NR12 is the performance of Symmetrical Constriction Structure in meander 36, while NR10 shows the satellite images taken in the last 2 years and coordinates are $64^{\circ} 40^{\prime} \mathrm{N}, 154^{\circ} 33^{\prime} \mathrm{W}$; NR11 shows the planform migration structure in details, and NR12 shows the statistical data of planform migration architecture elements and parameters of meander 36. NR13-NR15 is the performance of Upstream Rotation Constriction Structure in meander 30, while NR13 shows the satellite images taken in the last 2 years and coordinates are $64^{\circ} 42^{\prime} \mathrm{N}$, $154^{\circ} 28^{\prime} \mathrm{W}$; NR14 shows the planform migration structure in details, and NR15 shows the statistical data of planform migration architecture elements and parameters of meander 30. NR16-NR18 is the performance of Downstream Rotation Constriction Structure in meander 50, while NR16 shows the satellite images taken in the last 2 years and coordinates are $64^{\circ} 35^{\prime} \mathrm{N}, 154^{\circ} 21^{\prime} \mathrm{W}$; NR17 shows the planform migration structure in details, and NR18 shows the statistical data of planform migration architecture elements and parameters of meander 50. Images and coordinates information come from Google Earth and ACME Mapper

\subsubsection{Upstream Rotation Constriction Structure}

The process of outward expansion of the meandering loop slows down with curvature apex being closer to the upstream bend inflection, showing a tendency of counter-current rotation, and the trend of cut-off is starting gradually near the bend inflections. $K_{M}$ is less than 1 and $\Delta \theta$ is positive, this is the Upstream Rotation Constriction Structure. As is shown in Figure 4 NR13-NR15, NR13 shows that from years 2011 to 2013, the migration of the meander 30 in the Nowitna River is slow. According to the planform migration architecture of NR14 and characterization parameters of NR15, it can be seen that the value of S is $3.86, \mathrm{C}$ is 0.0012 , reflecting a greater degree of bending; $\Delta \theta$ is $12^{\circ}$ and $\Delta \theta^{\prime}$ is $-12^{\circ}$, indicating that the curvature apex is closer to the upstream bend inflection with the tendency of counter-current rotation. $\mathrm{K}_{\mathrm{M}}$ is 0.68 , indicating that the meander is in the constriction period with a greater degree.

\subsubsection{Downstream Rotation Constriction Structure}

The process of outward expansion of the meandering loop slows down with curvature apex being closer to the downstream bend inflection, showing a tendency of along-current rotation, and the trend of cut-off is starting gradually near the bend inflections. $\mathrm{K}_{\mathrm{M}}$ is less than 1 and $\Delta \theta$ is negative, this is the Downstream Rotation Constriction Structure. As is shown in Figure 4 NR16-NR18, NR16 shows that from years 2010 to 2013, the 
migration process of the meander 50 is not clear, and it is shown that value of $\mathrm{S}$ is 3064 and $\mathrm{C}$ is 0.0034 by the planform migration architecture of NR17 and characterization parameters of NR18, reflecting a greater degree of bending; $\Delta \theta$ is $-4^{\circ}$ and $\Delta \theta^{\prime}$ is $4^{\circ}$, indicating that the curvature apex is closer to the downstream bend inflection with the tendency of along-current rotation. $\mathrm{K}_{\mathrm{M}}$ is 0.72 , indicating that the river is in the constriction period with a greater degree.

\section{Discussion}

Combining the architecture elements with characterization parameters, the following ideal models of the meandering process may be concluded and established as 6 conventional models and 3 basic composite models (Figure 5).

\subsection{Expansion Migration Model}

\subsubsection{Symmetrical Expansion Migration}

The meandering channel continuously migrates laterally and the curvature apex is approximately shifting with linear movement. The value of $\mathrm{L}_{C}, \mathrm{~S}$, and $\mathrm{R}$ increases gradually, while the $\left|\mathrm{AX} \mathrm{X}_{\mathrm{MB}}\right|$ and $\mathrm{L}_{\mathrm{ML}}$ remain relatively stable with the slow decrease, $\mathrm{C}$ decreases gradually; $\theta_{\mathrm{U}}$ and $\theta_{\mathrm{D}}$ remain constant, $\Delta \theta$ and $\Delta \theta^{\prime}$ are basically maintained at $0^{\circ} . \mathrm{K}_{\mathrm{M}}$ is always greater than 1 , as is shown in Figure 5 (1), this is the meandering model of Symmetrical Expansion Migration. The meander 18 in NR1 (Figure 3) reveals this model.

\subsubsection{Upstream Rotation Expansion Migration}

The meandering channel continuously migrates laterally and the curvature apex is approximately shifting with the curvilinear movement towards the upstream. The value of $\mathrm{L}_{\mathrm{C}}, \mathrm{S}, \mathrm{R}$, and $\theta_{\mathrm{U}}$ increases gradually, while the $\left|A X_{M B}\right|$ and $L_{M L}$ remain relatively stable with slow decrease, $C$ and $\theta_{D}$ decreases gradually; $\Delta \theta$ is positive and increases gradually while $\Delta \theta^{\prime}$ is negative and decreases gradually. $\mathrm{K}_{M}$ is always greater than 1 , as is shown in Figure 5 (2), this is the meandering model of Upstream Rotation Expansion Migration. The meander 41 in NR4 (Figure 3) reveals this model.

\subsubsection{Downstream Rotation Expansion Migration}

The meandering channel continuously migrates laterally and the curvature apex is approximately shifting with curvilinear movement towards the downstream. The value of $L_{C}, S, R$, and $\theta_{D}$ increases gradually, while the $\left|A X_{\mathrm{MB}}\right|$ and $\mathrm{L}_{\mathrm{ML}}$ remain relatively stable with slow decrease, $\mathrm{C}$ and $\theta_{\mathrm{U}}$ decreases gradually; $\Delta \theta$ is negative and decrease gradually while $\Delta \theta^{\prime}$ is positive and increases gradually. $K_{M}$ is always greater than 1 , as is shown in Figure 5 (3), this is the meandering model of Downstream Rotation Expansion Migration. The meander 29 in NR7 (Figure 3) reveals this model.

\subsection{Constriction Migration Model}

\subsubsection{Symmetrical Expansion Migration}

The process of migrating laterally of the meandering channel slows down with the tendency of cut-off is beginning tardily near the bend inflections, and the curvature apex is approximately shifting with linear movement. The value of $\mathrm{L}_{\mathrm{C}}, \mathrm{S}$, and $\mathrm{R}$ increases slowly, while the value of $\left|\mathrm{AX} \mathrm{X}_{\mathrm{MB}}\right|, \mathrm{L}_{\mathrm{ML}}$, and $\mathrm{C}$ relatively decrease. $\Delta \theta_{\mathrm{U}}$ and $\Delta \theta_{\mathrm{D}}$ remain constant, $\Delta \theta$ and $\Delta \theta^{\prime}$ are basically maintained at $0^{\circ} . \mathrm{K}_{\mathrm{M}}$ is always less than 1 , as is shown in Figure 5 (4), this is the meandering model of Symmetrical Constriction Migration. The meander 36 in NR10 (Figure 4) reveals this model.

\subsubsection{Upstream Rotation Constriction Migration}

The process of migrating laterally of the meandering channel slows down with the tendency of cut-off is beginning tardily near the bend inflections, and the curvature apex is approximately shifting with curvilinear movement towards the upstream. The value of $\mathrm{L}_{C}, \mathrm{~S}$, and $\mathrm{R}$ increases gradually, while the value of $\left|\mathrm{AX}_{\mathrm{MB}}\right|, \mathrm{L}_{\mathrm{ML}}$, and $C$ relatively decrease. $\theta_{U}$ varies with early increase and later decrease, while $\theta_{\mathrm{D}}$ varies with early decrease and later increase and then decrease; $\Delta \theta$ is positive while $\Delta \theta^{\prime}$ is negative and both close to $0^{\circ}$. $\mathrm{K}_{\mathrm{M}}$ is always less than 1, as is shown in Figure 5 (5), this is the meandering model of Upstream Rotation Constriction Migration. The meander 30 in NR13 (Figure 4) reveals this model.

\subsubsection{Downstream Rotation Constriction Migration}

The process of migrating laterally of the meandering channel slows down with the tendency of cut-off is beginning tardily near the bend inflections, and the curvature apex is approximately shifting with curvilinear movement towards the downstream. The value of $\mathrm{L}_{\mathrm{C}}, \mathrm{S}$, and $\mathrm{R}$ increases gradually, while the value of $\left|\mathrm{AX} \mathrm{XB}_{\mathrm{MB}}\right|$, $\mathrm{L}_{\mathrm{ML}}$, and $\mathrm{C}$ relatively decrease. $\theta_{\mathrm{U}}$ varies with early decrease and later increase and then decrease, while $\theta_{\mathrm{D}}$ varies 
with early increase and later decrease; $\Delta \theta$ is negative while $\Delta \theta^{\prime}$ is positive and both close to $0^{\circ}$. $\mathrm{K}_{M}$ is always less than 1, as is shown in Figure 5 (6), this is the meandering model of Downstream Rotation Constriction Migration. The meander 50 in NR16 (Figure 4) reveals this model.

\subsection{Composite Migration Model}

The migration process of the meandering channel is accompanied by changes in the topography, hydrodynamic, sedimentary environment and so on. Therefore, in the nature channel, it is more inclined to see the complexes of the above 6 model. While the basic composite models are these three: Symmetrical Expansion - Constriction Migration, Figure 5 (7), Upstream Rotation Expansion - Constraint Migration, Figure 5 (8), Downstream Rotation Expansion - Constriction Migration, Figure 5 (9). Other more complex migration situations can be basically combined by these patterns.

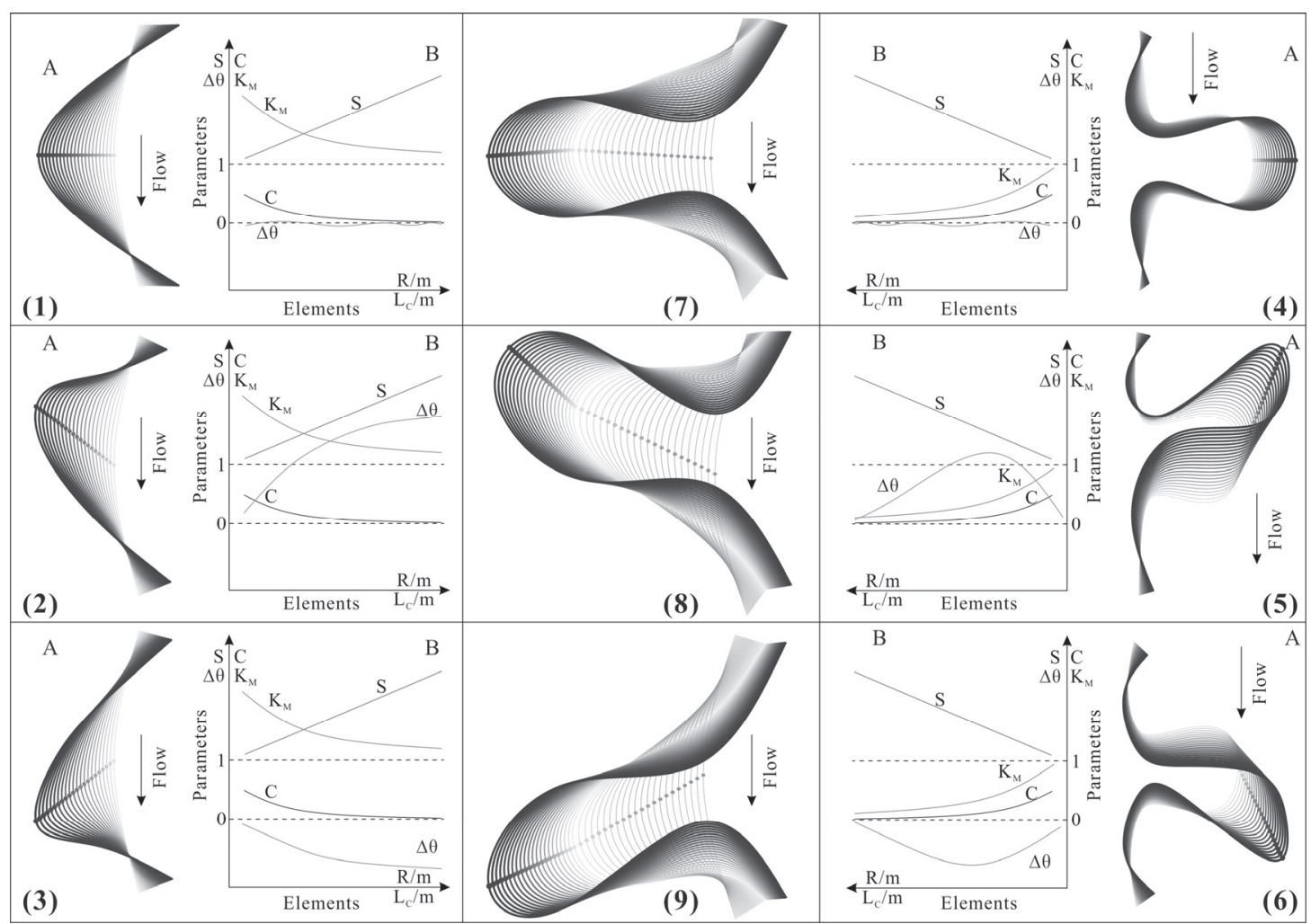

Figure 5. Planform migration model of the meandering channel under the ideal condition

A is the simplified schematic diagram of the process of channel migration, and B is the simplified relation between the values of characterization parameter and structural elements. (1) is model of Symmetrical Expansion Migration; (2) is model of Upstream Rotation Expansion Migration; (3) is model of Downstream Rotation Expansion Migration; (4) is model of Symmetrical Expansion Migration; (5) is the model of Upstream Rotation Constriction Migration; (6) is the model of Downstream Rotation Constriction Migration; (7) is the model of Symmetrical Expansion - Constriction Migration; (8) is the model of Upstream Rotation Expansion - Constraint Migration; (9) is the model of Downstream Rotation Expansion - Constriction Migration.

\subsection{Comparison and Prediction Application}

Comprehensively speaking, the most advantages of the models demonstrated here mainly fall at two points, one is the method of quantification as well as dynamic perspective, and the other is the potential preponderance of meandering process prediction.

The pre-existing models, as can be seen in Figure 6, mostly display the architecture of a meandering river in a comparatively static manner (Figure $6 \mathrm{~A}$ and C), which is inadequate though. Simultaneously, the structure of migration process is also illustrated in theoretical results without the practical application (Figure $6 \mathrm{~B}$ and D). They all avoids a characterization of quantification and process. That's what the new models highlight. For the planform structure, the demonstration of $\mathrm{A}$ and $\mathrm{C}$ in Figure 6, there is no instruction about the centerline, bend 
inflection, or curvature apex and so on, nor the specific definition of the key dynamic parameters. Relatively, our model in Figure 2 illuminate the parameters both from static and dynamic elements systematically and integrally, providing a possible technique to make a quantitative characterization on all kinds of meandering rivers. On the other hand, the geomorphologic migration architecture is still qualitative simplicity in the Figure $6 \mathrm{~B}$ and $\mathrm{D}$, and when it was taken into illustrating an actual outcrop, surely the incoordination would show as a lack of quantitative characterization. Whilst, the planform migration model of the meandering channel showed in Figure 5 combined with the satellite outcrops and characterization parameters. Therefore, making the migration architecture more practical and sensible.

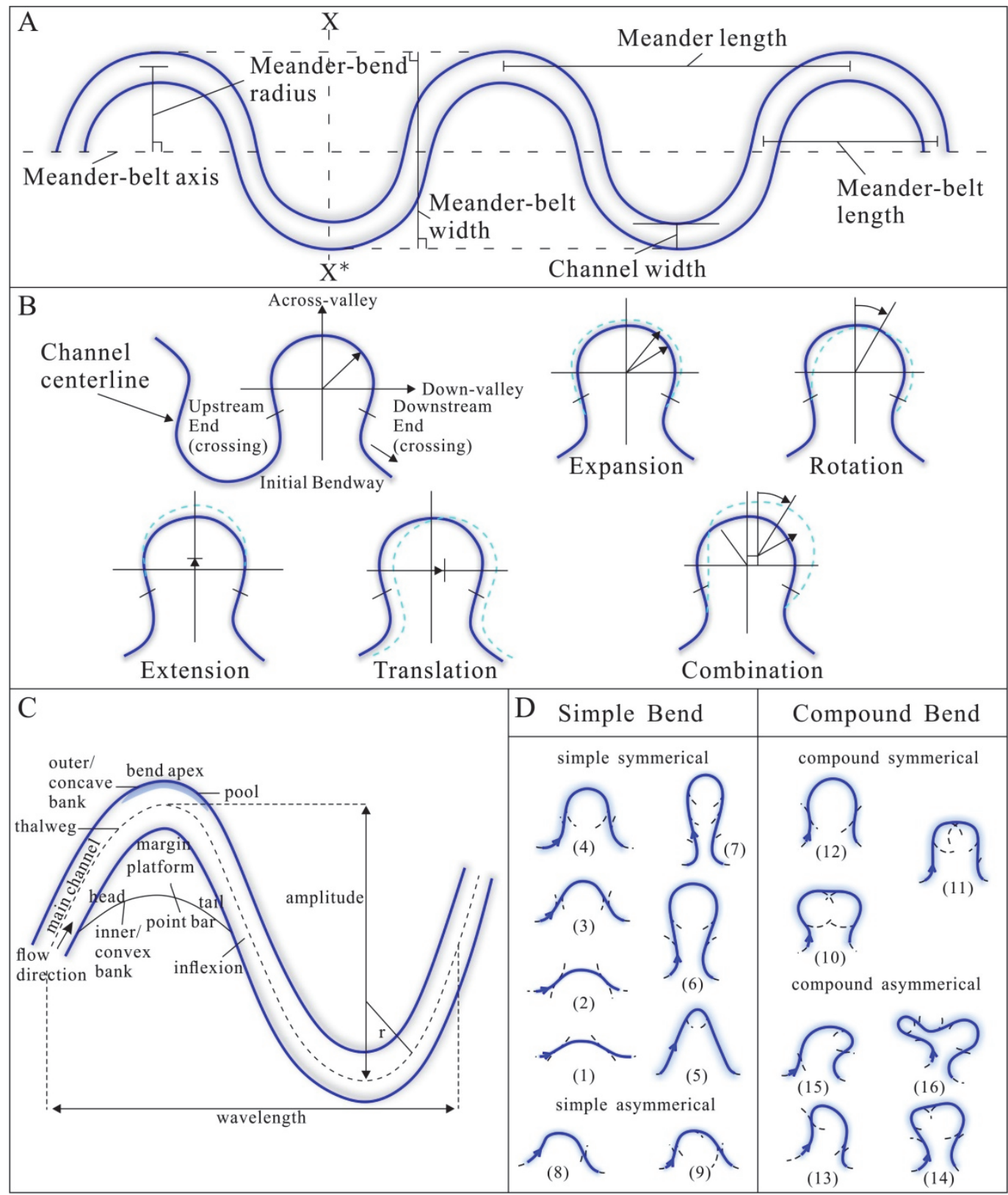

Figure 6. The commonly used morphodynamics models of the meander. (A) Map view of meander belt with the definition of morphometric parameters (van de Lageweg, 2013). (B) Bend migration types (Klaassen \& Masselink, 1992; Mithun et al., 2012). (C) Terminology and parameters of a meander planform(Kasvi et al., 2017). (D) Scheme for evolution and classification of meander loops(Brice, 1974)

One of the meaningful application of this idea of migration model is that it may provide a quantitative prediction of migration patterns for a river, which has never been mentioned before. Structures showed in Figure $6 \mathrm{~B}$ and D discuss the issues about the meandering migration, but they are so pure and unilateral that can only be utilized to 
plot an existing structure, not to forecast. Nevertheless, in this paper, we put forward the concept of characterization parameters of $\mathrm{S}, \mathrm{C}, \Delta \theta, \Delta \theta^{\prime}$, and $\mathrm{K}_{\mathrm{M}}$, whose application bring about the models in Figure 5 . These models, based on the quantitative parameters, can play a certain predictive role on the migration tendency. Just take the meander 18 of Nowitna River for example (Figure 3. NR1, NR2), currently meander 18 is in the status of Symmetrical Expansion Migration Model, with the constant decreasing of $\mathrm{K}_{\mathrm{M}}$ whose value is always greater than 1. As the meandering process continuing, it can be speculated that the $\mathrm{K}_{\mathrm{M}}$ will pass by the value of 1 and carry on declining. Thus the meander will change to the architecture of Symmetrical Expansion Migration (Figure 5). Moreover, combined with the factors of geology and so on, it may also transfer to the model of Upstream Rotation Constriction Migration and Downstream Rotation Constriction Migration.

Of course, though we may get a way to realize the quantitative representation of the architecture of a meandering channel, the possible forcings leading to the development of these different styles are still a great challenge, which should be our next target.

\section{Conclusion}

Though the structure characterization of the Nowitna River, this research mainly solved the following question:

(1) Comprehensive architecture elements are summed up with 17 static elements and 12 dynamic elements, and 5 kinds of new characterization parameters are prosed with quantitative characterization for the meandering channel.

(2) 50 meanders in Nowitna River is investigated and 6 of them are chosen for meticulous characterization with architecture elements and characterization parameters. Through the quantitative characterization for the meanders, 6 migration structures are obtained with parameter information.

(3) The migration structures are discussed as models of 6 conventional and 3 basic composite models. Through different combinations, it can be used to describe and show the other migration structure. However, this study also has its limitations and it is still only one the tip of the iceberg of rivers around the world. Therefore, the methods and models in the study surely need further investigated in the future work.

\section{References}

Blum, M., Martin, J., Milliken, K., \& Garvin, M. (2013). Paleovalley systems: Insights from Quaternary analogs and experiments. Earth-Science Reviews, 116, 128-169. https://doi.org/10.1016/j.earscirev.2012.09.003

Brice, J. C. (1974). Evolution of meander loops. Geological Society of America Bulletin, 85(4), 581-586.

Debnath, J., Pan, N. D., Ahmed, I., \& Bhowmik, M. (2017). Channel migration and its impact on land use/land cover using RS and GIS: A study on Khowai River of Tripura, North-East India. The Egyptian Journal of Remote Sensing and Space Science. https://doi.org/10.1016/j.ejrs.2017.01.009

Feng, Z. (2013). Chinese sedimentology (Second Edition). Beijing: Petroleum Industry Press.

Ghinassi, M., Nemec, W., Aldinucci, M., Nehyba, S., Özaksoy, V., \& Fidolini, F. (2014). Plan—form evolution of ancient meandering rivers reconstructed from longitudinal outcrop sections. Sedimentology, 61(4), 952-977. https://doi.org/10.1111/sed.12081

He, Y., \& Wang, W. (2008). Sedimentary rocks and sedimentary facies. Beijing: Petroleum Industry Press.

Hooke, J. (1984). Changes in river meanders: A review of techniques and results of analyses. Progress in Physical Geography, 8(4), 473-508. https://doi.org/10.1177/030913338400800401

Hu, G., Chen, F., Fan, T., \& Hu, Y. (2017). Subdividing and comparing method of the fluvial facies reservoirs based on the complex sandbody architectures. Petroleum Geology \& Oilfield Development in Daqing, 36(2), 12-18. https://doi.org/1000-3754 (2017) 02-0012-07

Hu, G., Fan, T., Chen, F., Jing, Y., Wand, H., \& Song, L. (2017). From Reservoir Architecture to Seismic Architecture Facies: Characteristic Method of a High-Resolution Fluvial Facies Model. Acta Geographica Sinica, 91(2), 465-478.

$\mathrm{Hu}, \mathrm{H}$. (2016). Adjustment measures of remaining oil tapping based on sand body structure. Lithologic Reservoirs, 28(4), 113-120. https://doi.org/10.3969/j.issn.1673-8926.2016.04.016

Ielpi, A., \& Ghinassi, M. (2014). Planform architecture, stratigraphic signature and morphodynamics of an exhumed Jurassic meander plain (Scalby Formation, Yorkshire, UK). Sedimentology, 61(7), 1923-1960. https://doi.org/10.1111/sed.12122

Kasvi, E., Laamanen, L., Lotsari, E., \& Alho, P. (2017). Flow Patterns and Morphological Changes in a Sandy 
Meander Bend during a Flood-Spatially and Temporally Intensive ADCP Measurement Approach. Water, 9(2), 106. https://doi.org/10.3390/w9020106

Klaassen, G. J., \& Masselink, G. (1992). Planform changes of a braided river with fine sand as bed and bank material. Paper presented at the 5th International Symposium on River Sedimentation.

Kondolf, G. M. (2006). River restoration and meanders. Ecology and Society, 11(2), 42.

Leeder, M. (1973). Fluviatile fining-upwards cycles and the magnitude of palaeochannels. Geological Magazine, $110(03), 265-276$.

Leopold, L. B. (1960). Flow resistance in sinuous or irregular channels: US Government Printing Office.

Leopold, L. B., \& Maddock, T. (1953). The hydraulic geometry of stream channels and some physiographic implications: US Government Printing Office.

Leopold, L. B., \& Wolman, M. G. (1957). River channel patterns: braided, meandering, and straight: US Government Printing Office.

Lin, Z. (2017). Channel planform migration architecture of meandering rivers. Journal of Geology \& Geophysics, 3(3). https://doi.org/10.4172/2381-8719-C1-009

Lin, Z., Shan, J., \& Chen, L. (2017a). Geomorphology Processes of Channel Planform Migration on Meandering Rivers. Acta Geologica Sinica (English Edition), 91, 134-135.

Lin, Z., Shan, J., \& Chen, L. (2017b). Meticulous Depiction and Genetic Mechanism of Unconformity Belt Structure. Earth Science Research, 6(2), 19. http://dx.doi.org/ 10.5539/esr.v6n2p19

Miall, A. D. (1985). Architectural-element analysis: a new method of facies analysis applied to fluvial deposits. Earth-Science Reviews, 22(4), 261-308.

Miall, A. D. (2013). The geology of fluvial deposits: sedimentary facies, basin analysis, and petroleum geology: Springer.

Miall, A. D. (2014). Fluvial depositional systems (Vol. 14): Springer.

Miall, A. D. (2016). Facies Models Stratigraphy: A Modern Synthesis (pp. 161-214): Springer.

Mithun, D., Dabojani, D., \& Misbah, U. (2012). Evaluation of meandering characteristics using RS \& GIS of Manu River. Journal of Water Resource and Protection, 4(03), 163-171. https://doi.org/10.4236/jwarp.2012.43019

Mu, L. (2000). Stages and characteristic of reservoir description. Acta Petrolei Sinica, 21(5), 103-108.

Schumm, S. A., \& Lichty, R. W. (1963). Channel widening and flood-plain construction along Cimarron River in southwestern Kansas: US Government Printing Office.

Schuurman, F., Kleinhans, M. G., \& Middelkoop, H. (2016). Network response to disturbances in large sand-bed braided rivers. Earth Surface Dynamics, 4(1), 25-45. https://doi.org/10.5194/esurf-4-25-2016

Shan, J., Zhao, Z., Li, F., Sun, L., Tang, N., Wang, B., \& Gao, H. (2015). Evolution Process and Historical Reconstruction of Meandering River:An example from Fuyu oil reservoir of Yangdachengzi Oil Production Plant in Jilin Oilfield. Acta Sedimentologica Sinica, 33(3), 448-458. https://doi.org/10.14027/j.cnki.cjxb.2015.03.003

Shi, S., Hu, S., Fen, W., \& Liu, W. (2012). Building geological knowledge database based on Google Earth software. Acta Sedimentologica Sinica, 30(5), 869-878.

Sui, X. (2006). A study on internal architecture of channel sand in meandering river. Northeast Petroleum University, Daqing Petroleum Institute.

van de Lageweg, W. (2013). Morphodynamics and sedimentary architecture of meandering rivers (Utrecht Studies in Earth Sciences 040). UU Depts. of Earth Sciences and Physical Geography.

Williams, G. P. (1978). Bank-full discharge of rivers. Water Resources Research, 14(6), 1141-1154. https://doi.org/10.1029/WR014i006p01141

Willis, B. J., \& Tang, H. (2010). Three-dimensional connectivity of point-bar deposits. Journal of Sedimentary Research, 80(5), 440-454. https://doi.org/10.2110/jsr.2010.046

Wolman, M. G., \& Miller, J. P. (1960). Magnitude and frequency of forces in geomorphic processes. The Journal of Geology, 68(1), 54-74. 
Wu, C., Ullah, M. S., Lu, J., \& Bhattacharya, J. P. (2016). Formation of point bars through rising and falling flood stages: Evidence from bar morphology, sediment transport and bed shear stress. Sedimentology, 63(6), 1458-1473. https://doi.org/10.1111/sed.12269

Wu, S., \& Wang, Z. (1999). A new method of non-marine reservoir flow unit study. Acta Sedimentologica Sinica, $17(2), 87-92$.

Xu, J., Cai, G., Li, B., Wu, J., Jin, D., You, L., ... Zhang, Q. (2016). Research progress in river geomorphology in China:In memory of 100-year anniversary of Shen Yuchang's birth. Acta Geographica Sinica, 71(11), 2020-2036. https://doi.org/10.11821/dlxb201611012

Xue, P. (1991). An introduction to reservoir models of point bar facies. Beijing: Petroleum Industry Press.

Yin, T., Zhang, C., Zhao, H., Fan, Z., \& Li, Z. (2001). Remaining oil distribution prediction based on high-resolution sequence stratigraphy. Petroleum Exploration and Development, 28(4), 79-82.

Zhu, X. (2008). Sedimentary petrology. Beijing: Petroleum Industry Press.

\section{Copyrights}

Copyright for this article is retained by the author(s), with first publication rights granted to the journal.

This is an open-access article distributed under the terms and conditions of the Creative Commons Attribution license (http://creativecommons.org/licenses/by/4.0/). 